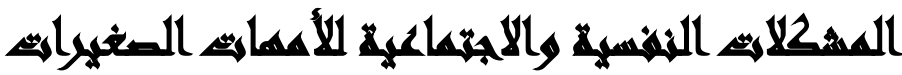

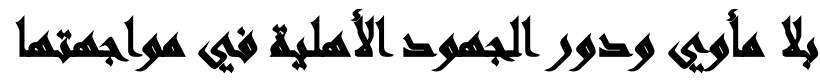

\section{[ᄉ]}

حنان محمود عبد الله سلامه(')- أحمد مصطفي العتيق(r)- مديحة مصطفي فتحي (r)

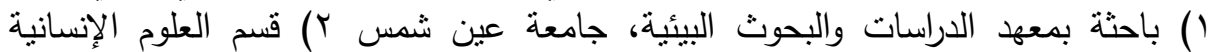

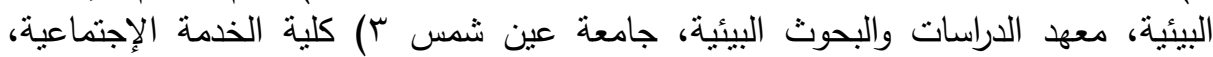
جامعة حلوان معهد الدراسات والبحوث البيئية.

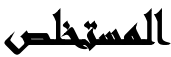

هدفت الدراسة الحالية إلي التعرف علي المشكلات النفسية والإجتماعية التي تواجه

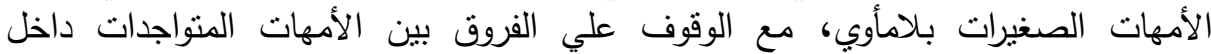

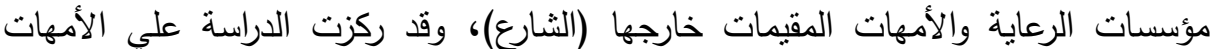

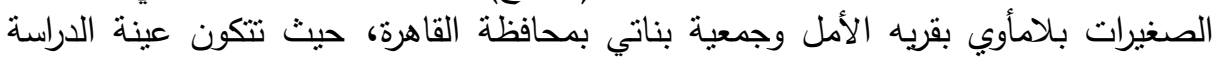

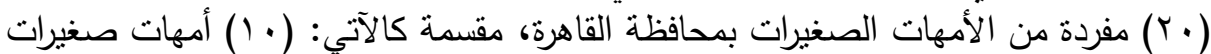

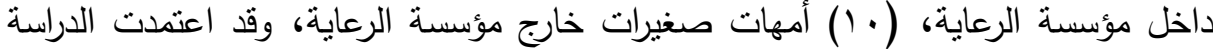

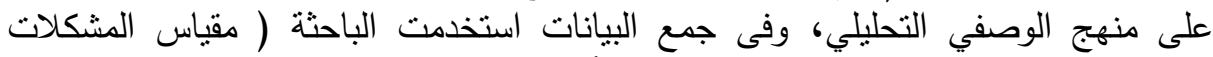

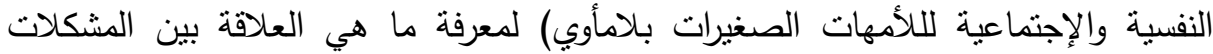

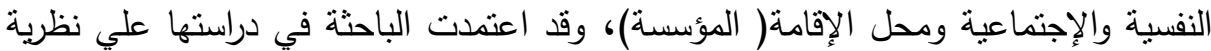

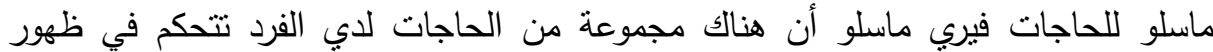

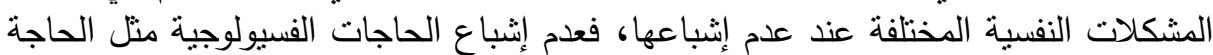

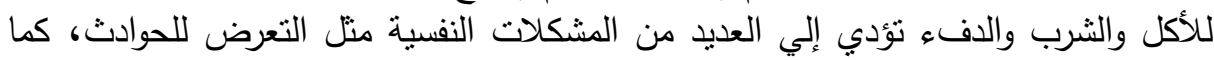

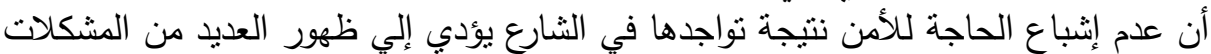

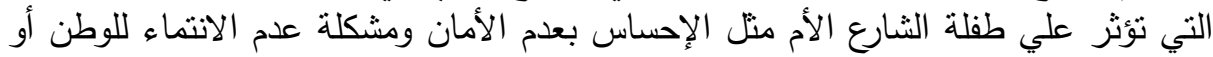

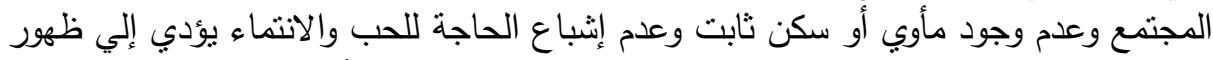

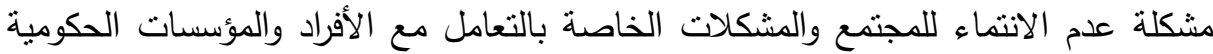
وكذلك مشكلة الثعور النقص والدوانية ومشكلة العدوان وكذلك مشكلة الخوف من الثناف المستقبل

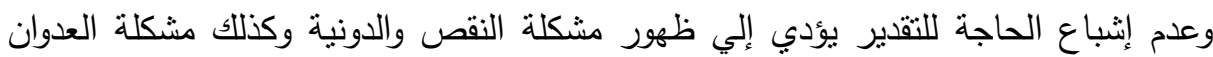

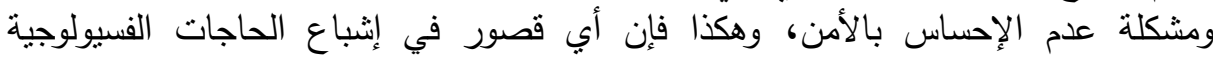
والنفسية لاي الطفلة الأم يؤدي إلي الاضطراب النفسي وكذلك يؤدي إلي المشكلات النفسية

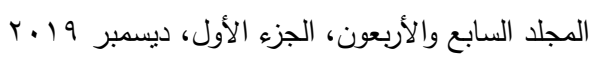




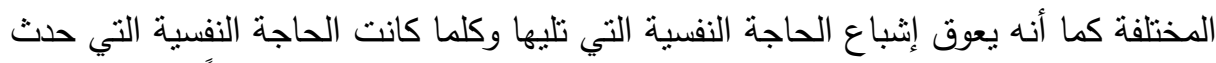

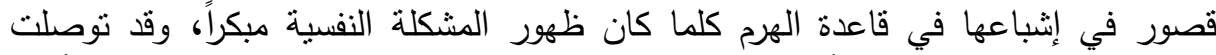

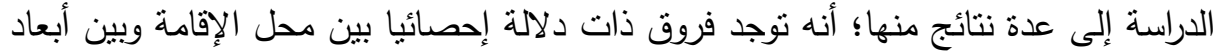

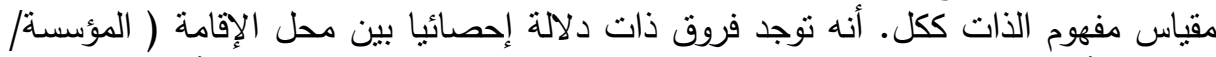

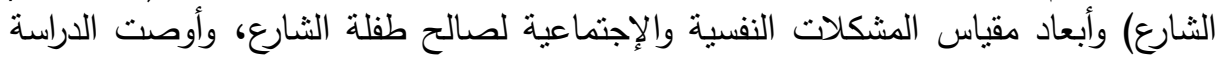

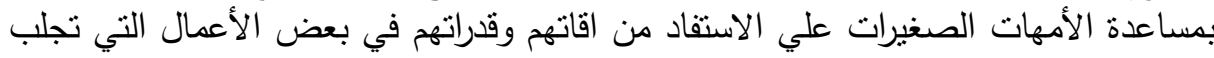

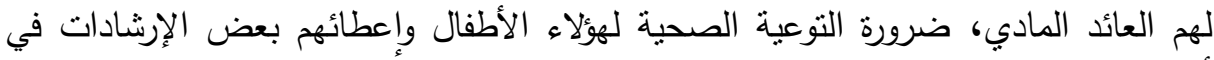
أماكن تواجدهم من قبل المشرفين الإجتماعين.

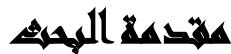

في مجتمعتا الحالية تثكل حقوق ورفاهية الطفل الثغل الثاغل للعالم أجمع، ليس لكون الطفل إنسان بالدرجة الأولي له حقوق منله منل غيره من فئات المجتمع وبل كونه يقع في فئه

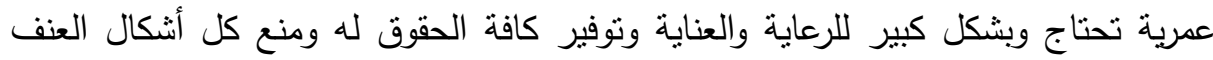
والإستغلال، وكان المنطلق الأساسي لهذا الأعلان هو أن البشريه مدينة للطفل بأفضل وله ماعندها من عطاء وأن الأباء والأفرادا والمنظمات التطوعية والسلطات المحلية والحكومية مطالبون جميعاً بالإعتراف بالحقوق المنصوص عليهاء الابهاء وبالحرص علي مراعاتها، يقول عبداله

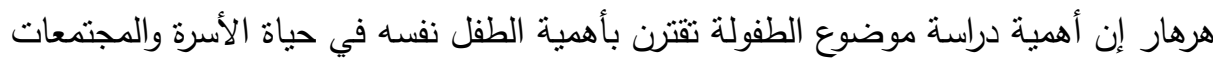
عموماً، فاطفل اليوم هو رجل الغد وإذا إردنا أن نحكم علي مستقبل مجتمع ما فلنبدأ بالطفل

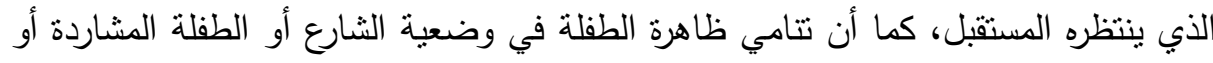
الطفلة العاملة والمستغلة جنساً كلها ظواهر تكثف عن بنف أزمة حضارية وإجنماعية يعيشها

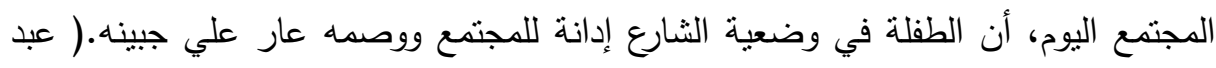

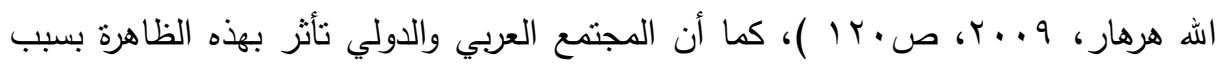

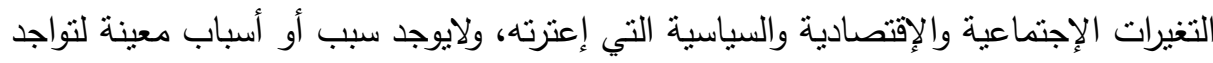

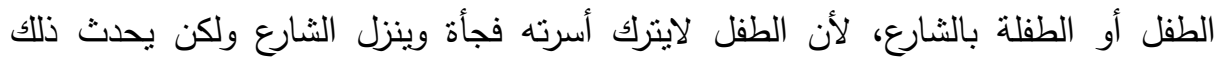
تدريجيا، لذلك فهناك عوامل وظروف منداخلة أساسها الأسرة ويدعمها النظام التعليمي لأني بالمدارس ونظام العمل بالورش وثقافة المناطق العشوائية، هذه الظروف المختلفة تهيء الطفلة

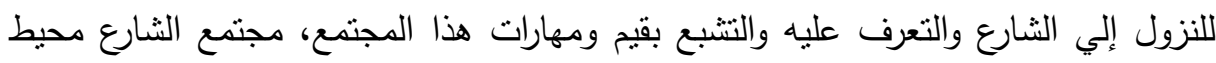

$$
\text { المجلد السابع والأربعون، الجزء الأول، ديسمبر } 9 \text { أ. }
$$


إجتماعي يوفر لها فرص الكسب والعمل واللعب والحرية، ويحقق لهم غريزة حب الإستطلاع،

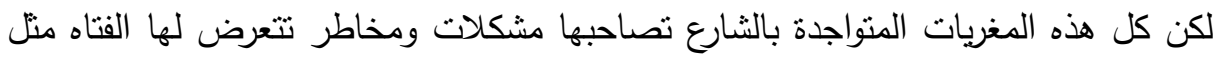

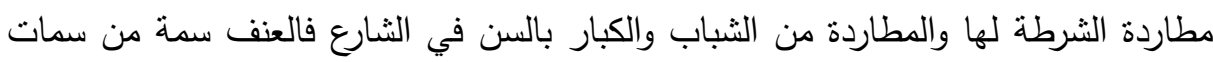

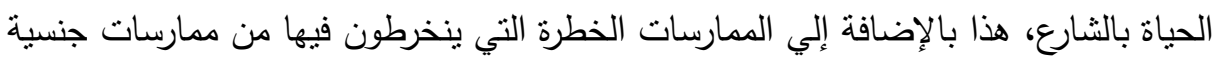

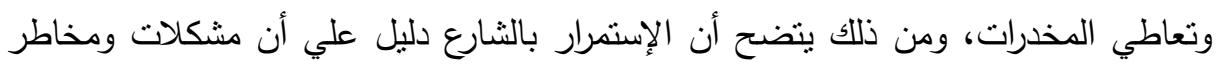
التواجد به غير طاردة بسبب المغريات المتواجدة بالثشارع، وبسبب المساندة التي يحصلون

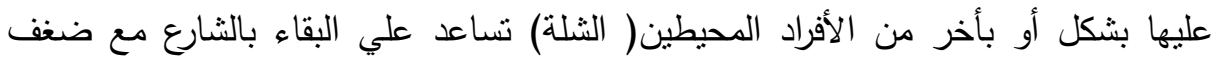

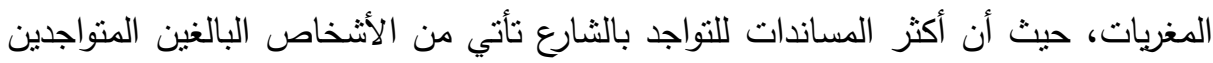
بالثارع والمتمكنين من حياة الثشارع والتنديب علي أساليب التعايش فيه وعلي إستراتيجيات

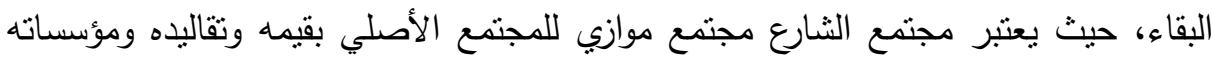

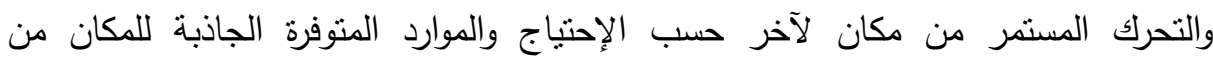
الإستراتجيات المهمه للتعايش والبقاء بالثشارع، ومن ذلك فإن جذب الطفلة الطبلة من الثارع لإعادة

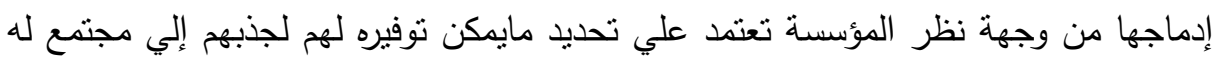
إطار الحماية أي المجتمع الأساسي الذي ينافس مجتمع الثارع بمغرياته وموارده.

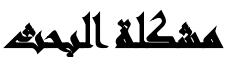

بالبحث والإطلاع علي الدراسات السابقة نجد أن المشكلات البحثية التي تعرضت

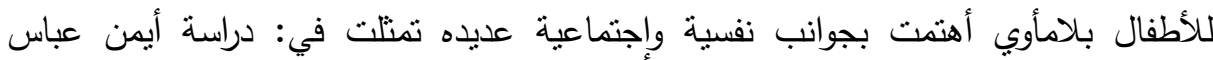

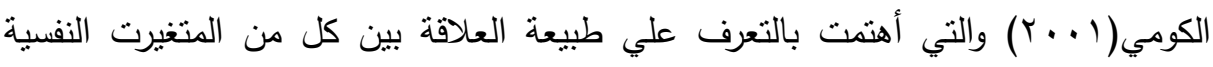

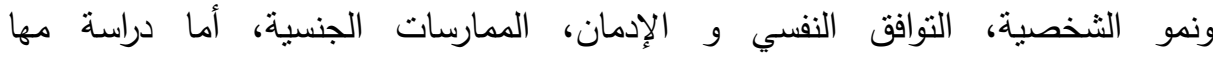

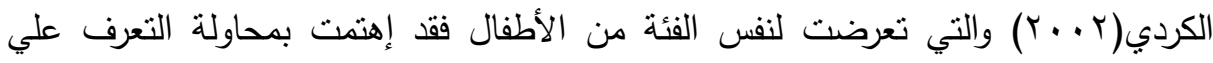

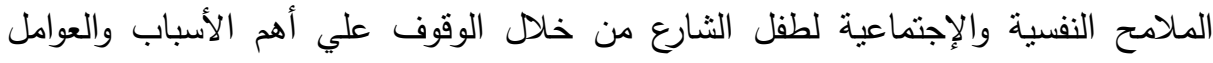

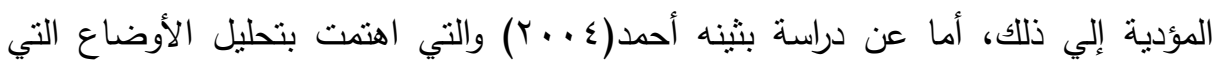
تحيط بطفل الثارع سواء كان ذللك في نطاق الأسرة أو في الثارع، أح عن دراسة (هانم

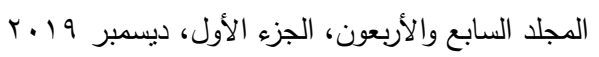


بسيوني، • ( Y) والتي أهتمت بالمشكلات النفسية والإجتماعية التي تواجه لطفلة الثارع الأم،

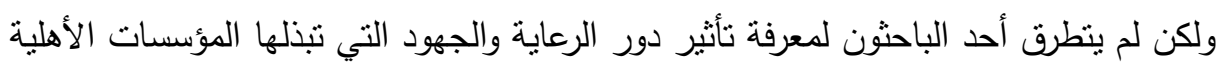

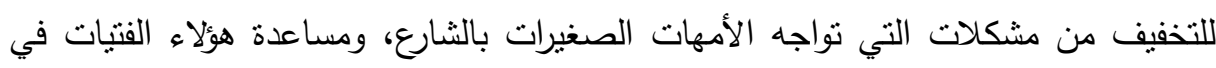

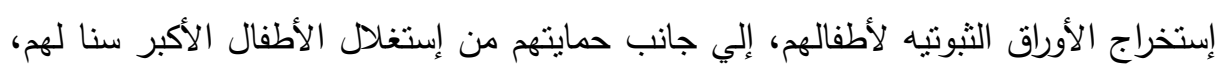

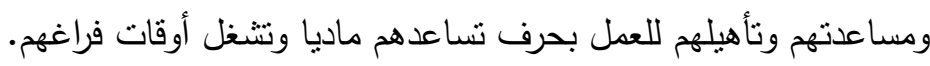

أسئل المهيث

( ) المشكلات النفسية التي تواجه الأمهات الصغيرات بلامأوي؟

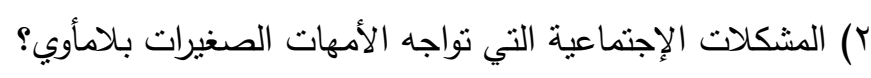

\section{أهar}

تستمد الدراسة الحالية أهميتها من أهمية الموضوع محل الدراسة:

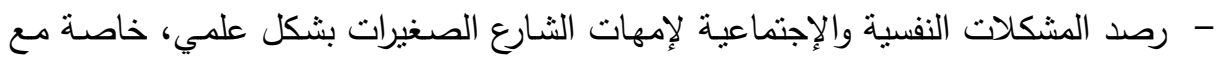
بدء الإهتمام بنوفير أماكن تأوي هؤلاء الفتيات من الثارع.

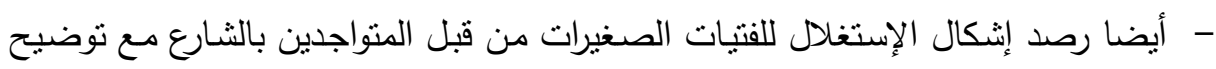

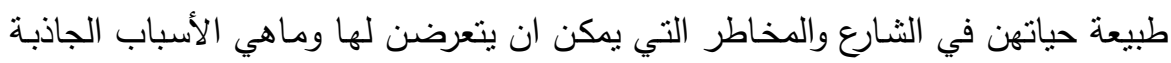
للفتاه لنزول الثارع. - دور الأسـرة في هـروب تلكـ الفتـاه، يعتبر نوجيـه وتوفير الرعايـة الإجتماعيـة للأكهـات الصنيرات أمر وواجب مجتمعي وأخلاقي، وعدم إثباع هذه الإحتياجات قد يدفع هؤلاء

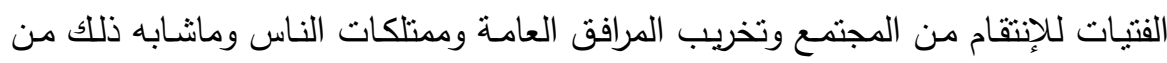
سلوكيات مدمرة للمجتمع. - - إنباع التخطيط كأسلوب علمي في مواجهة ظـاهرة الأمهات الصغيرات بلامـأوي ودعم

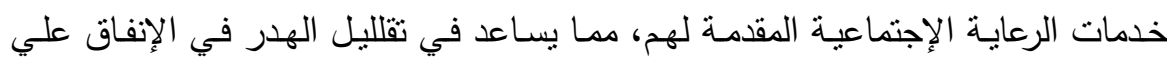

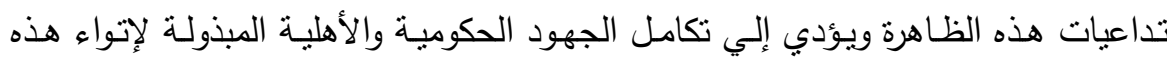
الظاهرة. 


\section{محسايت الهمهي}

تتمثل محدات البحث في الآتي:

أ- المجال البشرى: تكونت عينة الدراسة من (•r) فتاه، (•(1) أمهات صغيرات بلامأوي يقيمن داخل أحدي دور الرعاية، ( • () أمهات صغيرات بلامأوي يقيمن بالثارع. ب- المجال المكانى: محافظة القاهرة، جمعية قرية الأمل وجمعية بناتي.

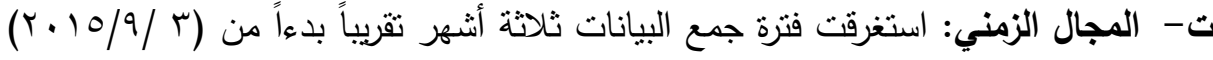

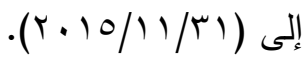

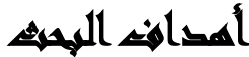

$$
\text { يمكن بلورة أهداف البحث فيما يلي: }
$$

ا ـ التعرف على المشكلات النفسية التي تواجه طفلة الثارع الأم. لون. r. التعرف علي المشكلات الإجتماعية التي تواجه طفلة الثارع الأم.

r. التعرف علي دور المؤسسات الأهلية تجاه طفلة الثارع الأم.

\section{هزوره الهمبث}

1-توجد فروق ذات دلالة إحصائيا بين عينتين من الأطفال بلا مأوي ( الأمهات الصغيرات)

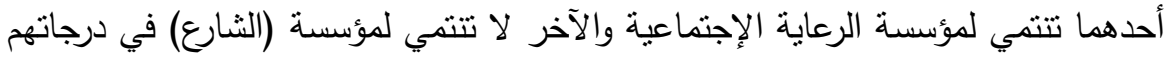

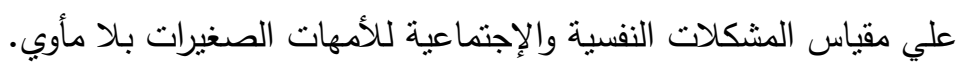
r-توجد علاقة ارتباطية بين الخصائص الإجتماعية ومقياس المشكلات النفسية والإجتماعية لكأكهات الصغيرات بلا مأوي. 


\section{همخاهيه المهيد الأهاسية}

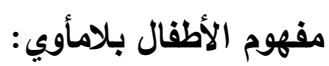

- فمنظمة الصحة العالمية (W.H.O) تجدهم ( الأطفال تحت الخطورة )؛ كونهم نلاك الفئة التي تجعل من الثارع مأوي أو مكاناً للاسترزاق والعيش سواء بصورة كلية أو

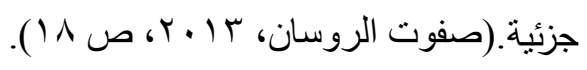

- تعريف الأمم المتحدة ( UNITED NATION) " وضعت الأمم المتحدة تعريفاً لأطفال الثوارع علي أنهم أي طفل ذكر أم أنثي، قد اتخذ من الثارع ( بما يشتمل عليه المفهوم

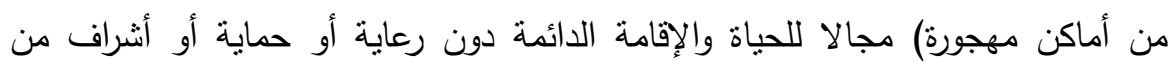

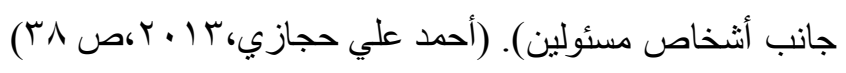

Operational Definition وعلى هذا يمكن التوصل إلى صياغة التعرف الإجرائي

$$
\text { الذي سوف تسنتد إلية الدراسة الراهنة: }
$$

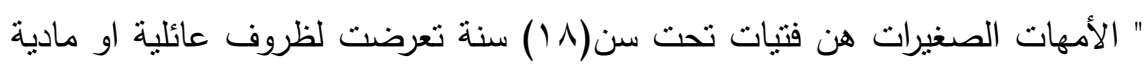

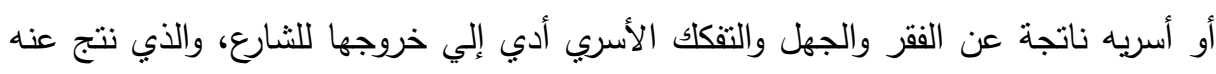

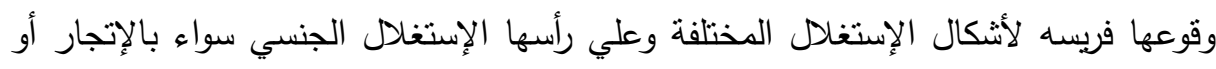

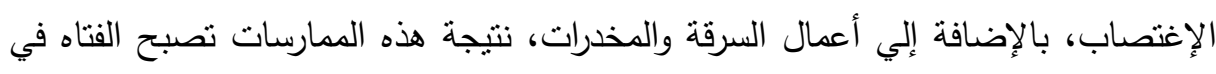
هذا السن أم ولم تكتمل شخصيتها ولاتكوينها الجسماني والعقلي. المشكلات النفسية والإجتماعية: عرف(bob) المشكلة النفسية بأنها:المشكلة التي ترتبطة

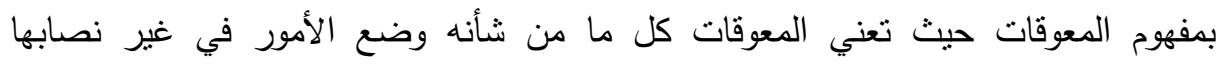

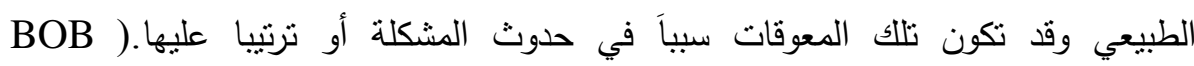
(FRANKLIN,1986

- - تعريف المشكلة النفسية من وجهة نظر علم النفس علي أنها نقص يواجهه الكائن الحي

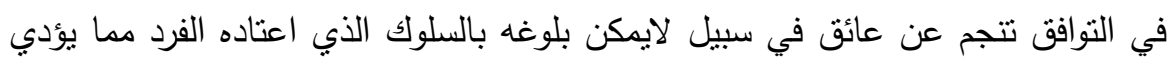

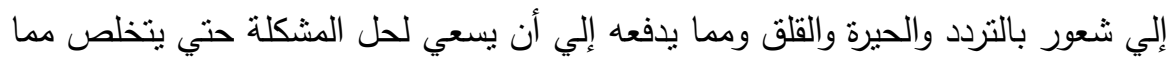

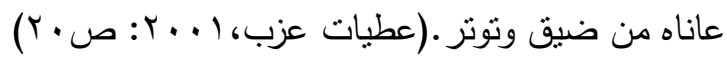


- تعرف المؤسسة الإيوائية: أيضا بأنها المنشأة الحكومية أو الأهلية التي تقوم بايواء الأطفال

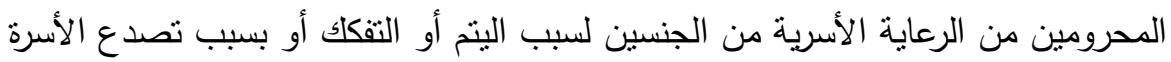

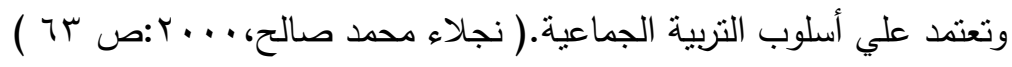

- تعرف المؤسسة الإيوائية: بأنها مؤسسة إجتماعية تخصصة فئسئة في رعاية فئة من فئات

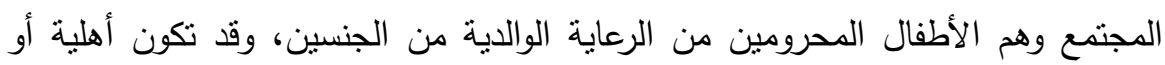

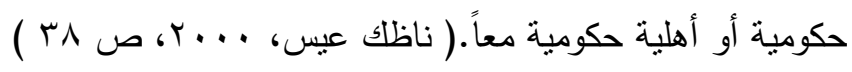

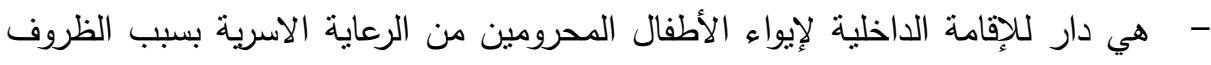
الصعبة التي تحول بينهم وبين استمرار معيثتهم داخل نطاق أسرهم الطبيعية كالأطفال

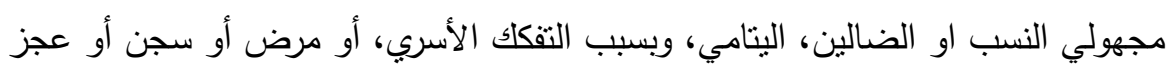

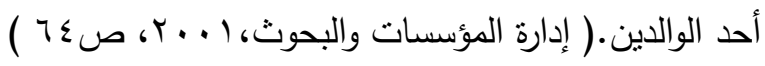

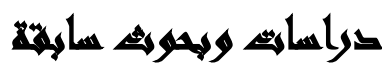

هناك العديد من الدراسات السابقة التى تتاولت الأطفال بلا مأوي، فمن خلال الاطلاع

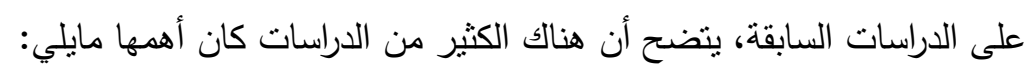
أولاً : الدراسات التي تتاولت المشكلات النفسية والإجتماعية وعلاقتها بالأطفال بلا مأوي

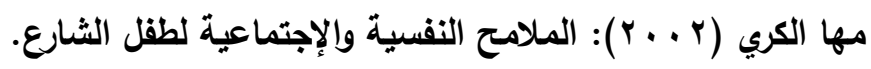
هدفت الدراسة إلي محاولة التعرف علي الملامح النفسية والإجتماعية لطفل الثنارع من خلال الوقوف علي أهم الأسباب والعوامل المؤدية إلي ذلك، حيث إعنمدت الدراسة علي منهج

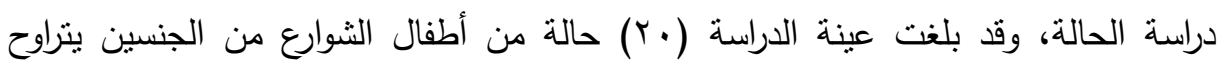

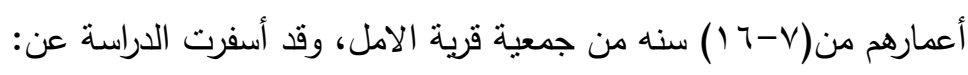


أن معظم أطفال العينة يعتمدون علي الثارع إعنمادا كليا بنسبة(•٪\%) للذكور

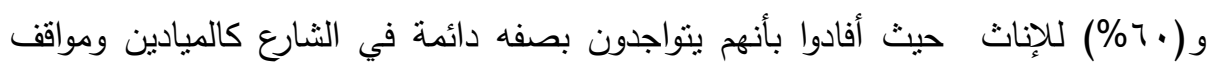

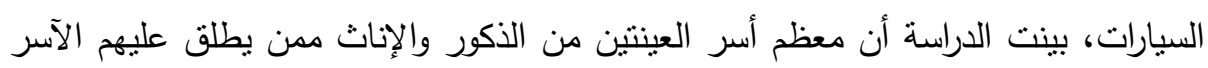

غير الكاملة بأنكالها المختلفة( طلاق - وفاة احد الوالدين - زواج احد الوالدين أو كليهما). دراسة شارلوت بروج (r...r) الحقوق الإنسانية للأطفال، أطفال الشوارع في أمريكا

يعاني أطفال الثوارع في أمريكا الوسطي من حرمانه ممن حقوقهم الإنسانية، حيث

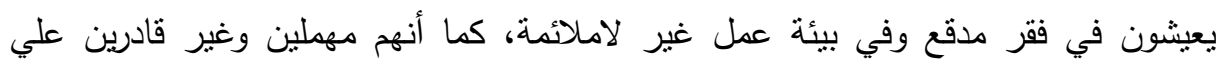

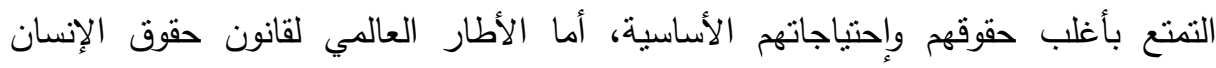
للأطفال يتكون أساسا من ميثاق حقوق الطفل مايخصه من بعض المبادئ، وإحيط بهذا

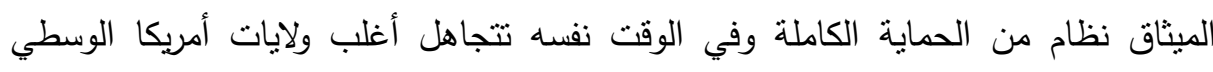

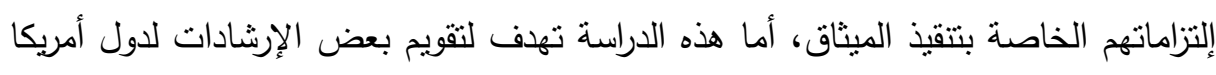
الوسطي من خلال نموذج يسمي (U.pp.p2) يهدف لإعتراف هذه الولايات بإحتياجات هؤلاء الأطفال وذلك من خلال التطبيق العادل والتتفيذ الفعال لحقوق الإنسان. ثانياً: الدراسات التي تناولت مفهوم الأطفال بلا مأوي.

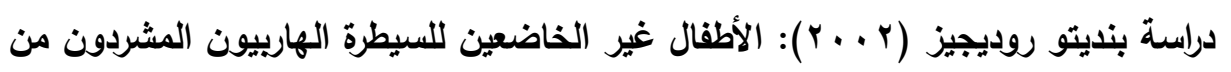
الثباب وأطفال الشوارع في نيويورك والبرازيل. تقارن هذه الدراسة بين أطفال الثوارع في نيويرك وبين اطفال الثوارع في البرازيل ومن فئن خلال ملاحظة وإجراء المقابلات مع(·ل) (1) طفل هارب واطفال شوارع، تم توثيق الرحلة

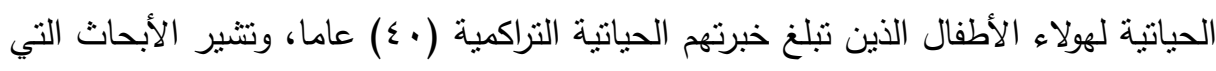

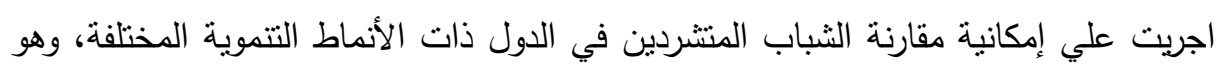
مايعني أن الظاهرة عالمية أما العامل المشترك بين أطفال الثوارع في الولايات المتحدة

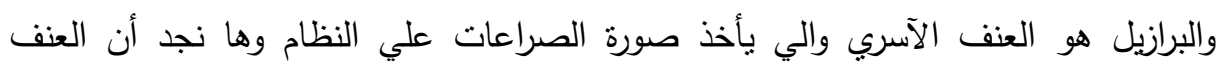

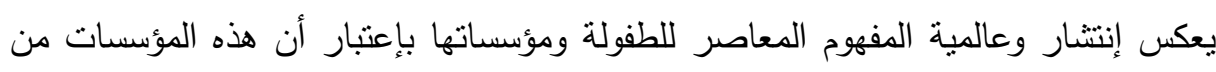
أحد حقوقهم وعلي المستوي المحلي، فأن التعارض في تفسير حقوق الاطفال لصالح الاسرة 
والحكومة والاسواق الحرة، يؤثر حتما علي الأطفال وينتج عنه نوع من الصراع والتوتر بين

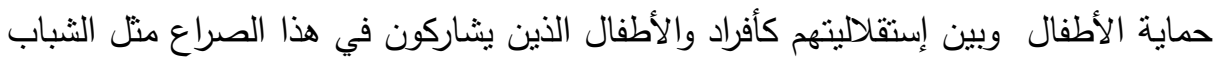
الرافضين للعنف في منازلهم يعبرون عن رفضهم بالرحيل عندئذ لايصبحون هم الهذف النهائي

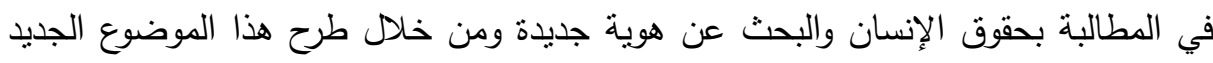
تتمكن من تصميم وتتفيذ سياسات إجتماعية تدعم تماسك الاسرة وتقلل من عالمية الظاهرة. قدري مصطفي (2008): الحياة اليومية لأطفال الشوارع في الخرطوم في السودان.

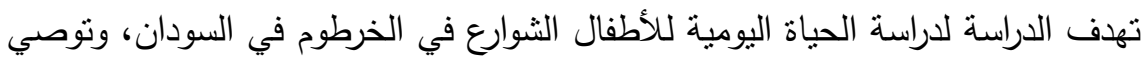

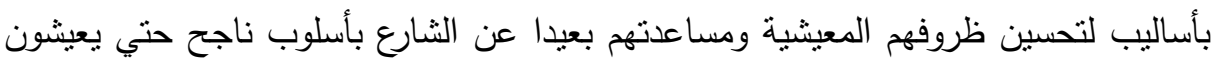

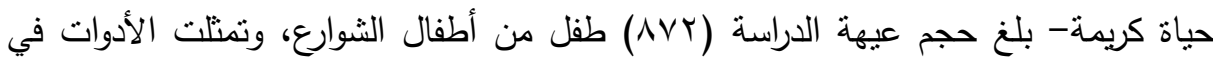

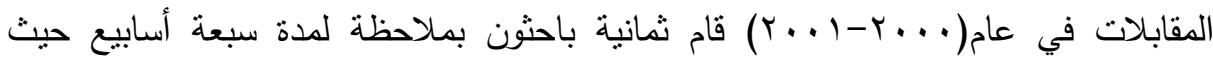

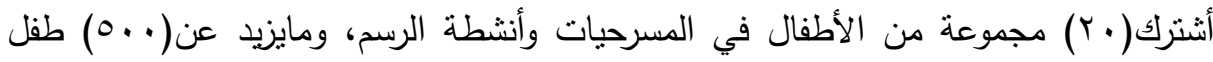
اشتركوا في المجموعة الكيفية والمقابلات الفردية، حوالي(AVY) من أطفال الثوارع تم تجميعم ومايريد ومعاينتهم، وقد أسفرت الدراسة عن:

أن تقريبا نصف عدد الأطفال كان بيلغ عمرها(ع () عاما أو أقل حياتهم اليومية رمزت التهات

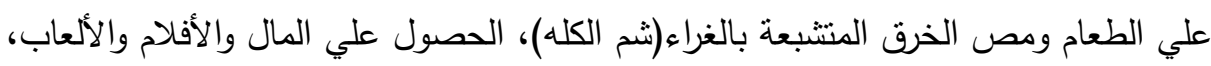
الأولاد أثتغلوا بالأعمال الثناذة الغريبة وأحيانا السرقة والتسول والعمل الجنسي، وكان بتهن

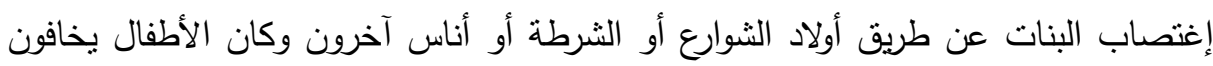
من القبض عليهم وضربهم وسجنهم عن طريق السلطات . ثالثاً: الدراسات التي تناولت دور المؤسسات الإيوايئة: دراسة عواطف عطفي منتصر ( 9 . . r) دور الإخصائي الإجتماعي مع جماعات الأطفال بلا مأوي لجذبهم لمؤسسات الرعاية الاجتماعية.

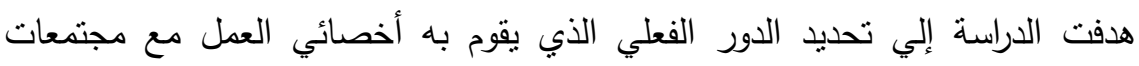
أطفال بلا مأوي لجذبهر لمؤسسات الرعاية الاجتماعية في ضوء الدراسة النظرية واللائحة 
التتفيذية للمؤسسات، تحديد الصعوبات التي تعوق ممارسة أخصائي العمل مع جماعات أطفال بلا مأوي لدوره المهني، اعتمدت الدراسة علي منهج المسح الإجتماعي الثامل للاخصائيين

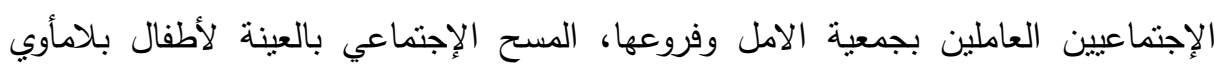

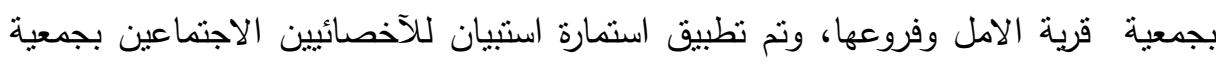

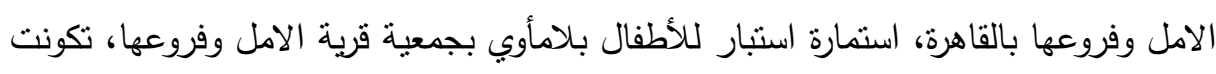

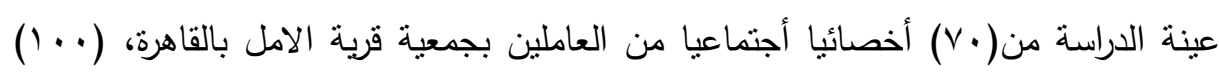

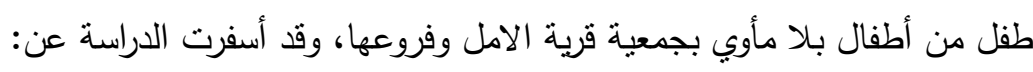

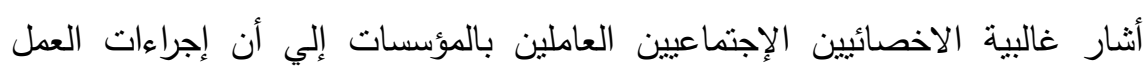

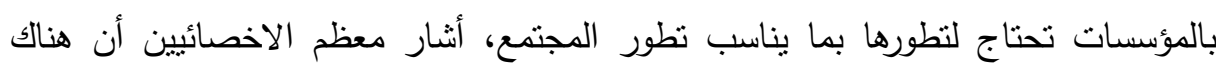
معوقات ترجع بعضها للطفل وبعضها للاخصائي نفسه وبعضها للمؤسسة.

دراسة تيم ميركر( 9 . . †): خصائص أسر ومقدمي الرعاية لأطفال الثوارع في الدوريت

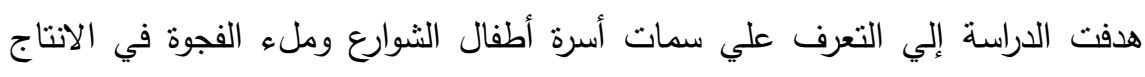

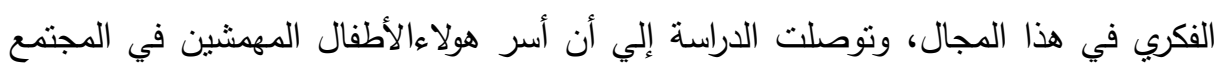

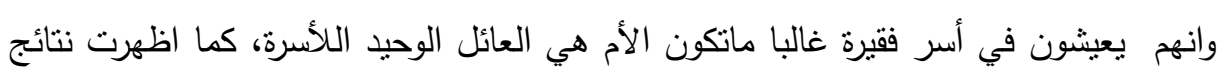
الدراسة أن فئة قليلة هي التي عبرت عن عدم معرفة الخدمات الاجتماعية التي تستهدف مساعدة أطفال بلا مأوي.

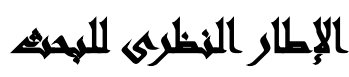

يعيش أطفال العصر الراهن حتي وهم في كنف أسرهم شروطا بالغة التعقيد والتفكل وقوة الضغوط الإقتصادية الإجتماعية والنفسية التي قد لاتسعفهم أجهزتهم العقلية والمعرفية والنفسية

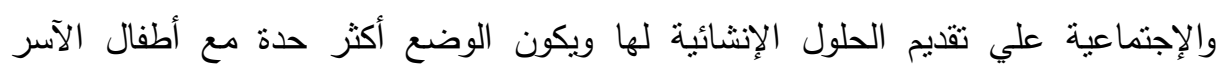

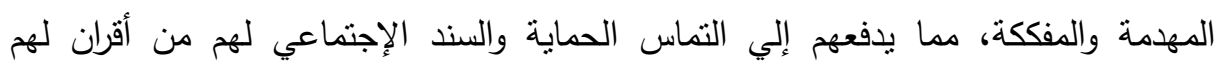

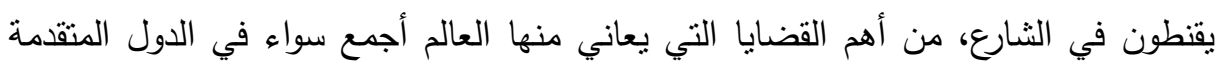
والنامية قضية أطفال الثوارع رغم الاختلاف في نسبة نواجد تلك الظاهرة بين هذه الدول( آمال

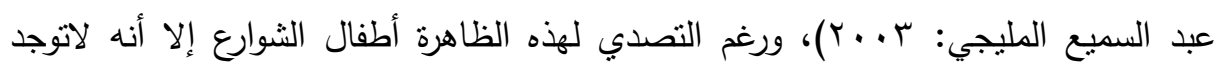


إحصائيا دقيقة حول الظاهرة عربيا بشكل يمكن أن يساهم في التعرف علي أبعادها المختلفة،

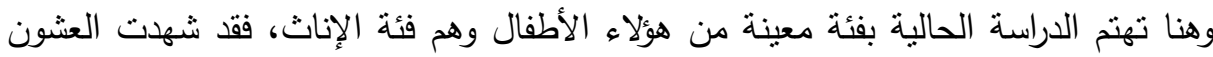

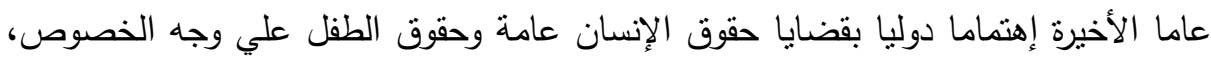

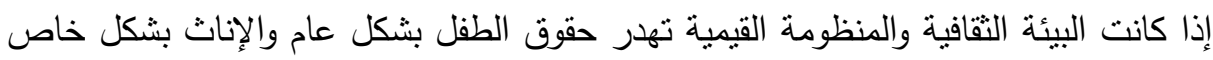

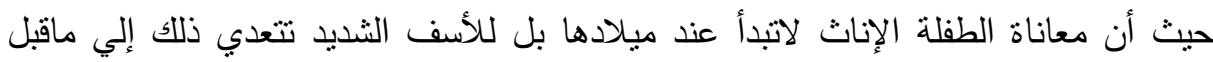
عملية الميلاد، ويظهر ذلك في التراث التقافي الذي يوضح الخوف والرعب من أن أن يكون المولود أنثي، وإنعكاس هذا الواقع النقافي في صورة ماديا تنين تميز الطفل الذكر عن الطفلة

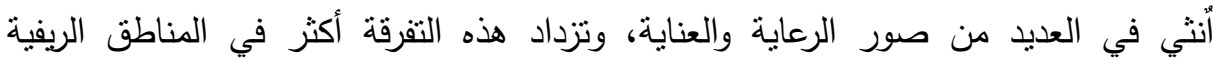

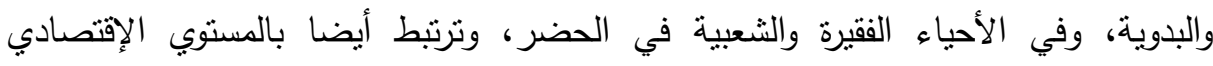

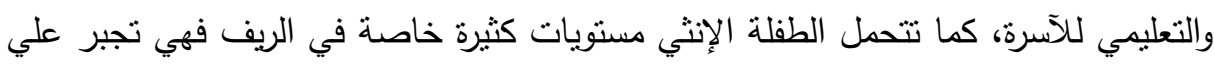

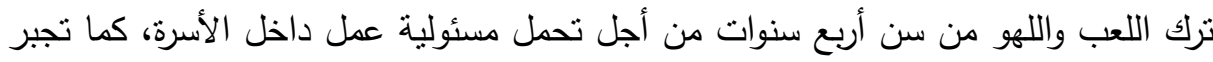

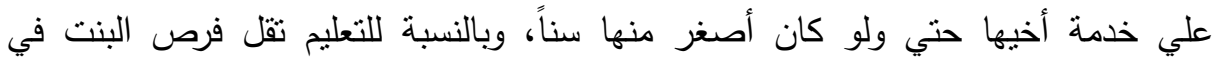
الحصول علي التعليم عن الذكور وذلك لعوامل قد تكون ثقافية أو إقتصادية،( سامي عصر ( . . r)، لذلك تزداد نسبة المنسرابات عن المنسربين، وإذا كنت الطفلة الإنثي تعاني من عدم المساواة وعدم الحصول علي حقوقها في الأوضاع العادية، فهذا يعطينا صورة مبدئية

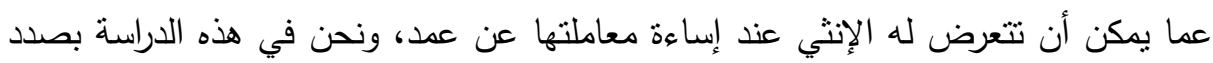

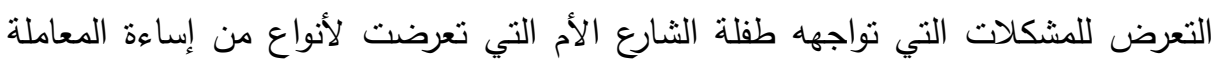
سواء إساءة معنوية أو إساءة جسدية، وما يترتب عن ذلك من مشكلات نفسية وإجتماعية تؤثز

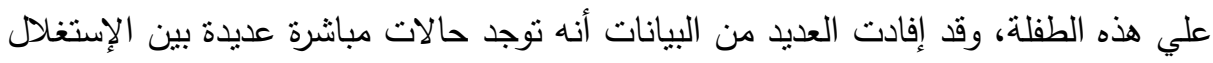
الجنسي للأطفال الثوارع حيث يساعد في هذا تدني ظروفهم الإجتماعية، وإفتقارهم للرعاية الآسرية التي تجلعهم غير واعين لمدي خطورة هذه الممارسات، وتؤدي هذه الممارسات الجنسية إلي تعرض الأطفال للعديد من المخاطر الصحية بما في ذللك الأمراض النفسية

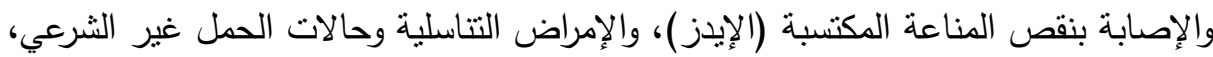


وإدمان المخدرات بالإضافة إلي ذلك يصبح هؤلاء الأطفال رهائن لواقع مشوه يسود فيه

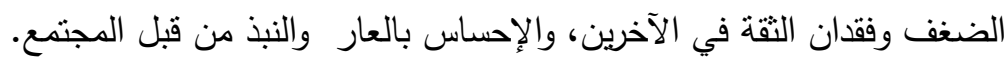

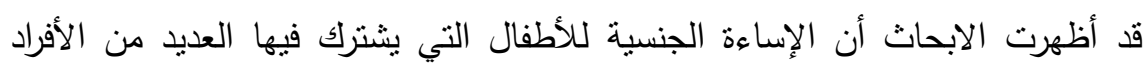

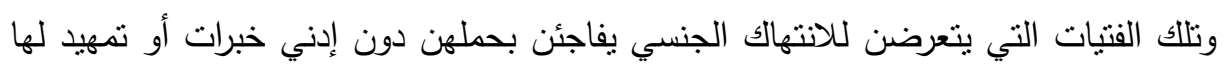

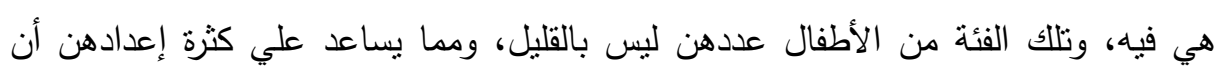

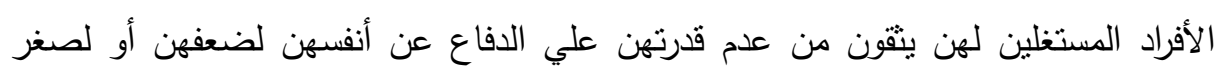

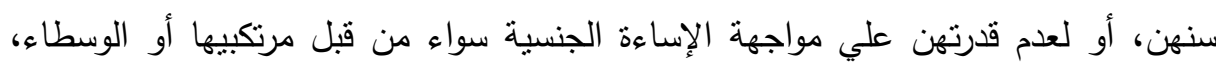

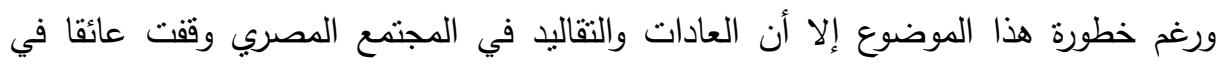

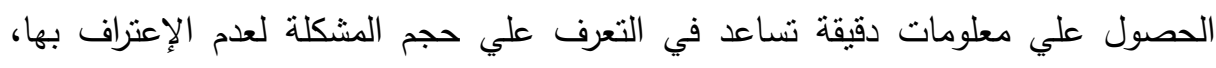
ولعدم الإبلاغ عنها، ولاثك أن هولاء الأطفال يعانون من العديد من المشكلات النفسية

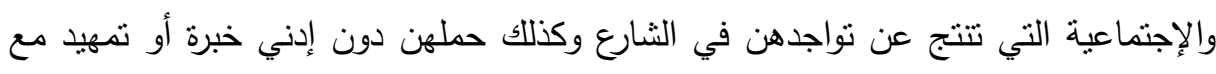
استغلال الآخرين لتلك الفئة من الأطفال.

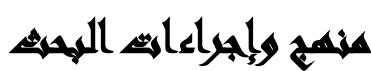

منهج البحث: من أجل تحقيق أهداف البحث قام الباحثون بإستخدام المنهج الوصفي

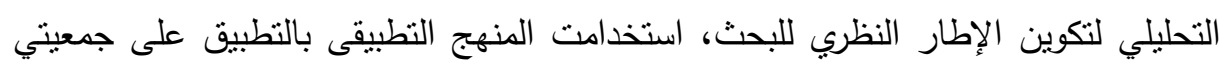
بناتي وقرية الأمل SOS، واستخدامت الأساليب الإحصائية للتحقق من صحة فروض البن البحث عينة البحث: قد أخذ الباحثون عينة من الأمهات الصغيرات من محافظة القاهرة، وقد

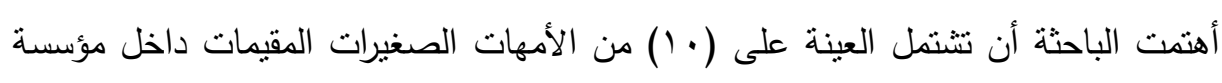

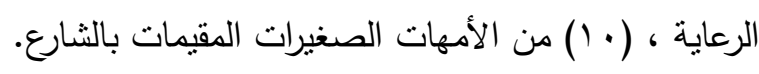
أدوات البحث: قام الباحثونب إستخدام مصدرين أساسين للمعلومات: 1) المصادر الثانوية: والتي تتمثل في الكتب والمراجع العربية والأجنبية ذات العلاقة

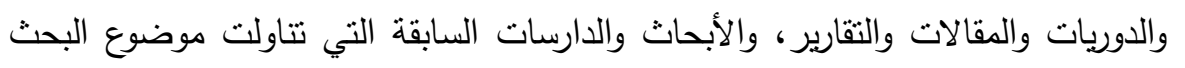

$$
\text { والمطالعة في مواقع الانترنت المختلفة. }
$$


r) المصادر الأولية: والتي تمتلت في جمع البيانات الأولية من خلال اختبار نفسي كاداه

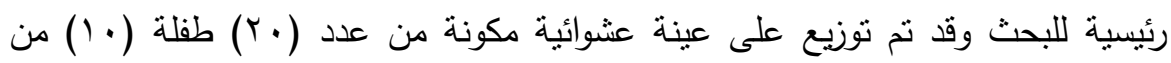
جمعية قرية الأمل وبناتي ( عينة تجريبية)، عدد(• () فتيات من المقيمات بالثارع (عينة

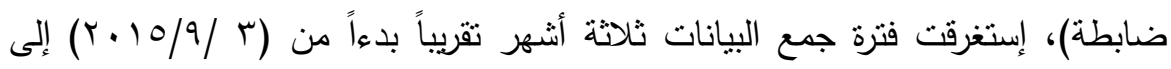

$$
\text { . }(r \cdot 10 / 1 r / r)
$$

r) وصف أداة القياس: قام الباحثون بتطبيق أختبار المشكلات النفسية والإجتماعية لطفلة الثارع الأم ( إعداد الباحثة) ينقسم أختبار المشكلات النفسية والإجتماعية لطفلة الثشارع الأم إلي إحدي عشر بعدا أساسية يشمل البعد الأول قياس النقص والدونية، ويشمل (0)

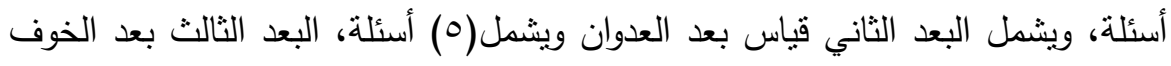

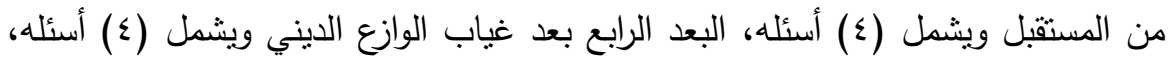

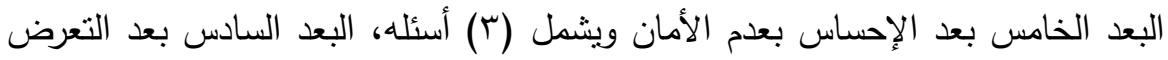

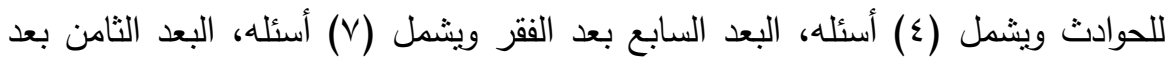
عدم وجود مأوي أو سكن ويشمل (0) أسئله، البعد التاسع بعد التعرض للأمراض والتلوث

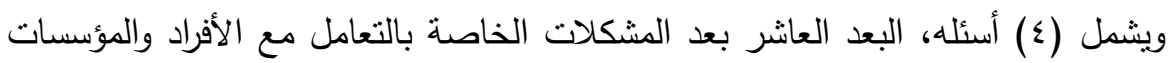

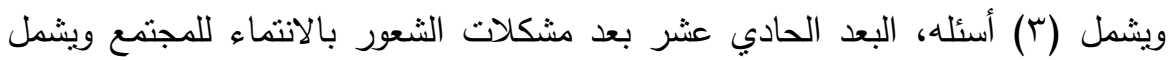

وقد قامت الباحثة بعمل صدق وثبات للأدوات في ضوء عينة الدراسة الحالية:

1. اختبار صدق المقياس:

أ- صدق الاتساق الداخلي: ولمزيد من التحليل، فقد قام الباحث بحساب صدق الاتساق

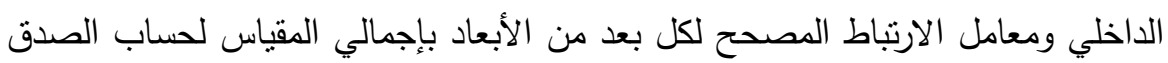
كالآتي: 
صدق الاتساق الاخلي لأبعاد لمقياس الأات:

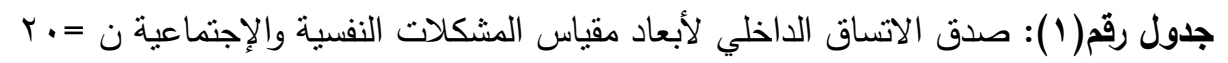

\begin{tabular}{|c|c|c|c|}
\hline الارتباط & \multicolumn{2}{|c|}{ ابعاد المقياس } & $b$ \\
\hline$(* *) \cdot, 99$. & معامل ارتباط بيرسون & \multirow{2}{*}{ الدونية والنقص } & \\
\hline$\cdot, .1$ & الدلالة المعنوية & & 1 \\
\hline$(* *) \cdot, \vee \leq \leqslant$ & معامل ارتباط بيرسون & \multirow{2}{*}{ 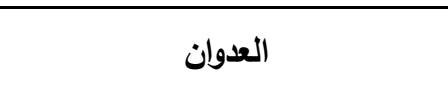 } & \multirow{2}{*}{ r } \\
\hline$\cdot, \cdot 1$ & الدلالة المعنوية & & \\
\hline$(* *) \cdot, 9 \mu r$ & معامل ارتباط بيرسون & \multirow{2}{*}{ الخوف من المستقبل } & \multirow{2}{*}{$r$} \\
\hline., .1 & الدلالة المعنوية & & \\
\hline$(* *) \cdot, 9 \wedge 1$ & معامل ارتباط بيرسون & \multirow{2}{*}{ غياب الوازع الديني } & \multirow{2}{*}{$\varepsilon$} \\
\hline$\cdot, \cdot 1$ & الدلالة المعنوية & & \\
\hline$(* *) \cdot, 9 \leq 0$ & معامل ارتباط بيرسون & \multirow{2}{*}{ الاحساس بعدم الامان } & \multirow{2}{*}{ - } \\
\hline$\cdot, \cdot, 1$ & الدلالة المعنوية & & \\
\hline$(* *) \cdot, 970$ & معامل ارتباط بيرسون & \multirow{2}{*}{ العرضة للحوادث } & \multirow{2}{*}{7} \\
\hline$\cdot, \cdot 1$ & الدلالة المعنوية & & \\
\hline$(* *) \cdot, 9 \vee \varepsilon$ & معامل ارتباط بيرسون & \multirow[b]{2}{*}{ الفقز } & \multirow{2}{*}{$\mathrm{v}$} \\
\hline$\cdot, \cdot 1$ & الدلالة المعنوية & & \\
\hline$(* *) \cdot 07$. & معامل ارتباط بيرسون & \multirow{2}{*}{ عدم وجود مأوي أو سكن } & \multirow[t]{2}{*}{$\wedge$} \\
\hline$\cdot, ., 1$ & الدلالة المعنوية & & \\
\hline$(* *) \cdot, 9 \vee \wedge$ & معامل ارتباط بيرسون & \multirow{2}{*}{ التعرض للأمراض والتلوث } & \multirow{2}{*}{9} \\
\hline$\cdot, \cdot 1$ & الدلالة المعنوية & & \\
\hline$(* *) \cdot, 971$ & معامل ارتباط بيرسون & \multirow{2}{*}{ مشكلات خاصة بالتعامل مع الأفراد } & \multirow{2}{*}{1.} \\
\hline$\cdot, \cdot 1$ & الدلالة المعنوية & & \\
\hline$(* *) \cdot, 9 \cdot 7$ & معامل ارتباط بيرسون & \multirow{2}{*}{ مشكلات الثعور بالانتماء للمجتمع } & \multirow{2}{*}{11} \\
\hline$\cdot, \cdot, 1$ & الدلالة المعنوية & & \\
\hline
\end{tabular}

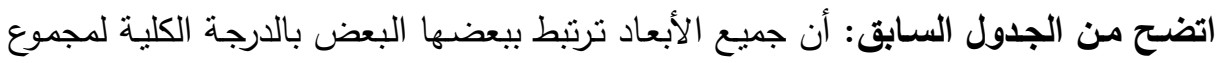

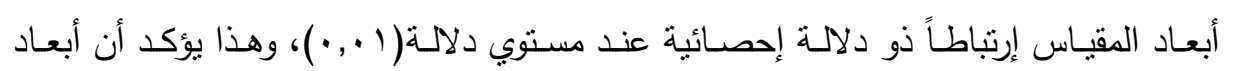
القياس تتمتع بدرجة عالية من الصدق.

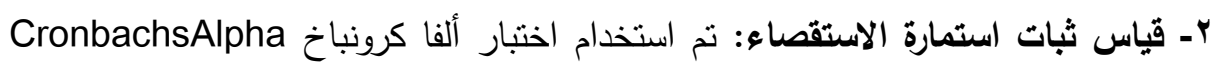
لاختبار ثبات بعدي الدراسة لجميع المتغيرات عدا البيانات الأولية. 
معهد الدراسات والبحوث البيئية - جامعة عين شمس به

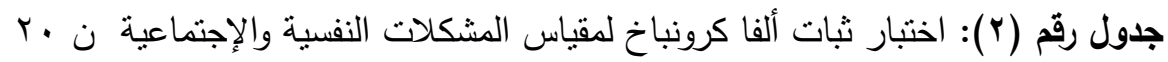

\begin{tabular}{|c|c|c|c|}
\hline معامل ألفا كرونباخ & عدد العبارات & البعد & p \\
\hline$\cdot, 9 \leqslant r$ & 0 & الدونية والنقص & 1 \\
\hline$\cdot, \wedge \vee \neg$ & 0 & العدوان & $r$ \\
\hline$\cdot, 91 \wedge$ & $\varepsilon$ & الخوف من المستقبل & $r$ \\
\hline$\cdot, 9 r V$ & $\varepsilon$ & غياب الوازع الديني & $\varepsilon$ \\
\hline$\cdot, 9 Y V$ & $r$ & الاحساس بعدم الامان & 0 \\
\hline$\cdot, 9 \cdot 9$ & $\varepsilon$ & العرضة للحوادث & 7 \\
\hline$\cdot, 97 \varepsilon$ & $\mathrm{V}$ & 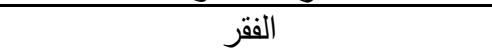 & $\mathrm{V}$ \\
\hline$\cdot, 9 \leq 9$ & 0 & عدم وجود مأوي أو سكن & $\Lambda$ \\
\hline$\cdot, 9 Y 0$ & $\varepsilon$ & التعرض للأمراض والتلوث & 9 \\
\hline$\cdot, 9 r q$ & r & التعامل مع الأفراد والمؤسسات الحكومية & 1. \\
\hline$\cdot, 9 \vee Y$ & $r$ & مشكلات الشعور بالانتماء للمجتمع & 11 \\
\hline$\cdot, 97 \varepsilon$ & $\varepsilon V$ & اجمالى ابعاد المقياس & \\
\hline
\end{tabular}

يوضح الجدول السابق: قيم الثبات لكل بعد من أبعاد المقياس والتي تراوحت بين (1) (AVT, ·)

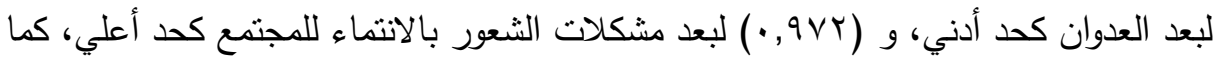

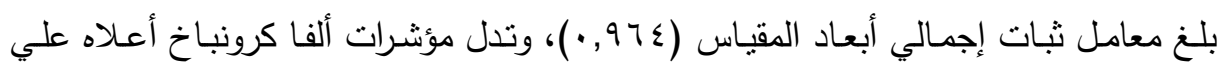
تمتع المقياس بمعامل ثابت عالٍ وبقدرتها على تحقيق أغراض الدراسة. 


\section{نمائي المهنه}

سوف ينت في هذا الجزء إلي أهم ماتوصلت إليه الدراسة الحالية من نتائج ومدي إتفاقها

واختلافها مع فروض الدراسة:

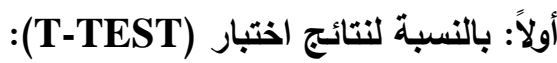

جدول رقم (ץ): اختبار TEST TET للفروق بين درجات التقبات المقيمات داخل المؤسسة والمقيمات خارجها علي مقياس المشكلات النفسية والإجتماعية النية

(عينة الاراسة الكلية)

\begin{tabular}{|c|c|c|c|c|c|c|c|}
\hline \multirow{2}{*}{ مستوية } & \multirow{2}{*}{ مستوية الالالةِ } & \multirow{2}{*}{ "قيمة } & \multicolumn{2}{|c|}{ الثارع (ن = · 1) } & \multicolumn{2}{|c|}{ المؤسسة (ن = 1 ) } & \multirow{2}{*}{ الأبعاد } \\
\hline & & & الانحراف & المتوسط & الانحراف & المتوسط & \\
\hline$\cdot, .0$ & (י,TH & $r, \varepsilon \wedge V$ & $r, 071$ & $1 \cdot, V$. & Y,YYI & $\mathrm{V}, \varepsilon$. & الدونية والنقص \\
\hline$\cdot, .0$ & $\cdot, \cdot T \varepsilon$ & $r, \varepsilon O V$ & $r, 0 \wedge \varepsilon$ & $1 \cdot, r$ & $r, \wedge 7 q$ & $v, r$. & العدوان \\
\hline$\cdot, .0$ & $\cdot, \cdot Y_{1}$ & rr,or & $r, 901$ & $\Lambda, \uparrow$. & $1, \wedge \vee \varepsilon$ & $0, \wedge$. & الخوف من \\
\hline., .0 & $\cdot, \cdot r V$ & $r, Y 70$ & $r, 991$ & $\Lambda, 0$. & $1, \wedge Y T$ & 7,1 . & غياب الوازع الديني \\
\hline لا توجد & $\cdot, \cdot \vee \wedge$ & $1, \wedge \div \wedge$ & $r, \varepsilon O r$ & $7, r$. & $1,0.7$ & $\varepsilon, 7$. & الاحساس بعدم \\
\hline., .0 & $\cdot, \cdot \leq \Lambda$ & $r, 1 \wedge \wedge$ & $r, 991$ & $\Lambda, 0$. & $1,7 \wedge \vee$ & $7, Y$. & العرضة للحوادث \\
\hline., .0 & $\cdot, \cdot \leq$. & $r, Y \backslash \wedge$ & ט & $1 \varepsilon, V$. & $r, r \cdot r$ & $1 \cdot, \Gamma$ & الفقر \\
\hline$\cdot, .0$ & $\cdot$, ro & r, & $\Gamma, \Lambda \cdot \wedge$ & $1, T, 0$. & $r, \vee \backslash \wedge$ & $\Lambda, \varepsilon$. & عدم وجود مأوي أو \\
\hline$\cdot, .0$ & $\cdot, \cdot r \varepsilon$ & $r, \leqslant 09$ & $r, q 1 \leqslant$ & $\Lambda, \varepsilon$. & $1, \wedge \wedge 9$ & $0, V$. & التعرض للأمراض \\
\hline$\cdot, .0$ & $\cdot, \cdot 11$ & r, 9TV & $r, \cdot 1 \varepsilon$ & $7,0$. & $1, r q \wedge$ & $\varepsilon, Y$. & مشكلات مع المؤسسات \\
\hline لالة توجد & $\cdot, \cdot 9$. & $1, \vee \vee 9$. & 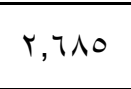 & 7,1 . & $1, v \cdot r$ & $\varepsilon, \Gamma$. & مشالانتماء للمجتات الثعور \\
\hline$\cdot, .0$ & $\cdot, \cdot 1 \varepsilon$ & $r, V \backslash q$ & $r \cdot, \varepsilon \cdot q$ & $1 \cdot 1,1$. & $19,1 \leq V$ & $V \cdot, r \ldots$ & إبعاد \\
\hline
\end{tabular}

• اتضح من الجدول السابق وجود فروق بين الأمهات الصغيرات المقيمات وغير المقيمات

في منوسط درجاتهم علي البعد النقص والدونية لصالح الأمهات الصغيرات المقيمات بالثارع. 
• اتضح من الجدول السابق وجود فروق بين الأمهات الصغيرات المقيمات وغير المقيمات

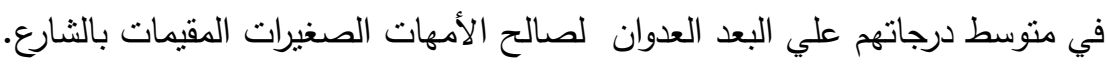

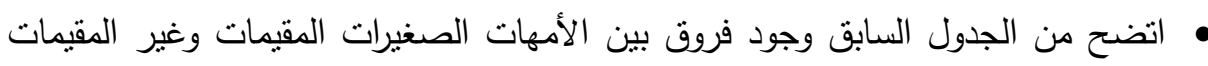

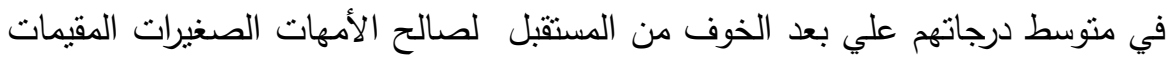
بالثارع. • اتضح من الجدول السابق وجود فروق بين الأمهات الصغيرات المقيمات وغير المقيمات في منوسط درجاتهم علي بعد غياب الوازع الديني لصالح الأمهات الصغيرات المقيمات بالثارع. • اتضح من الجدول السابق عدم وجود فروق بين الأمهات الصغيرات المقيمات وغير المقيمات في متوسط درجاتهم علي بعد الإحساس بعدم الأمان.

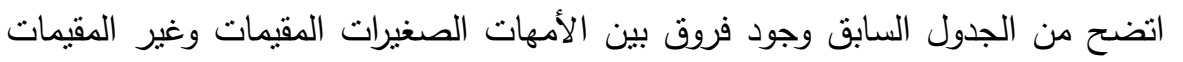

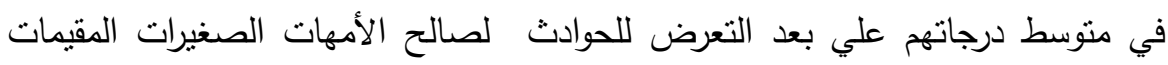
بالثارع. • اتضح من الجدول السابق وجود فروق بين الأمهات الصغيرات المقيمات وغير المقيمات في منوسط درجاتهم علي بعد الفقر لصالح الأمهات الصغيرات المقيمات بالثشارع.

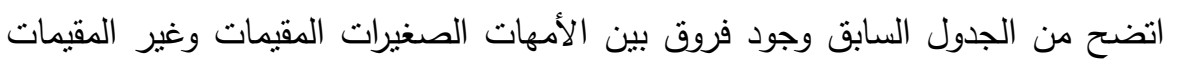
في متوسط درجاتهم علي بعد عدم وجود سكن أو مأوي لصالح الأمهات الصغيرات المقيمات بالثارع. • اتضح من الجدول السابق وجود فروق بين الأمهات الصغيرات المقيمات وغير المقيمات

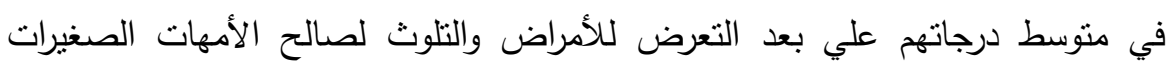
المقيمات بالشارع. اتضح من الجدول السابق وجود فروق بين الأمهات الصغيرات المقيمات وغير المقيمات

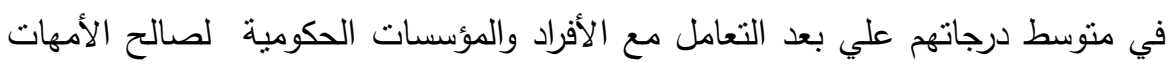


الصغيرات المقيمات بالثارع. • اتضح من الجدول السابق عدم وجود فروق بين الأمهات الصغيرات المقيمات وغير

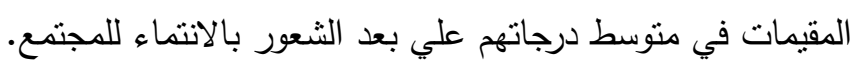

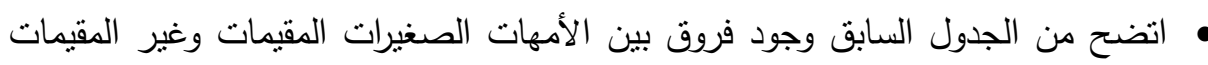
بالمؤسسة في منوسط درجاتهم علي إجمالي أبعاد المقياس المستخدم في الدراسة لصنالح الأمهات الصغيرات غير المقيمات بالمؤسسة.

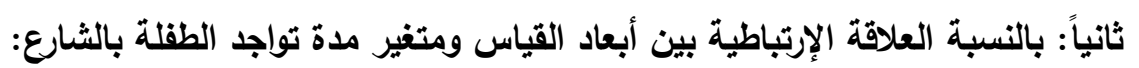

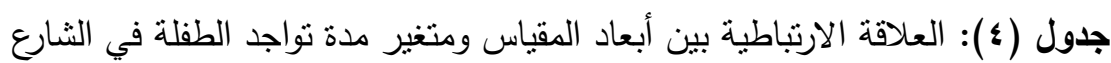

\begin{tabular}{|c|c|c|c|}
\hline \multicolumn{2}{|c|}{ مدة التّوجد في الشارع } & \multirow{2}{*}{ ارتباط بيرسون } & \multirow{2}{*}{ المتغيرات } \\
\hline الشارع & الموئسسة & & \\
\hline$\cdot, Y \leqslant Y$ & $\cdot, 1 \vee 9-$ & معامل الارتباط & \multirow{2}{*}{ الدونية } \\
\hline$\cdot, 0.1$ & $\cdot, 7 Y$. & الدلالة المعنوية & \\
\hline$\cdot, 1 \leq r$ &., .79 & معامل الارتباط & \multirow{2}{*}{ 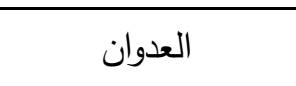 } \\
\hline$\cdot, 79 \leq$ & $\cdot, \wedge \leqslant 9$ & الدلالة المعنوية & \\
\hline$\cdot, 1 \vee \leqslant$ &., 19 & معامل الارتباط & \multirow{2}{*}{ 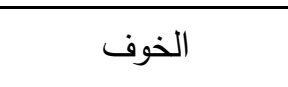 } \\
\hline$\cdot, 7 \pi \cdot$ &., 091 & الدلالة المعنوية & \\
\hline$\cdot, r \cdot 0$ & $\cdot, I V Y-$ & معامل الارتباط & \multirow{2}{*}{ غياب الوازع الديني } \\
\hline., 079 & מזוד & الدلالة المعنوية & \\
\hline$\cdot, 10$ & $\cdot, 10 \%-$ & معامل الارتباط & \multirow{2}{*}{ الإحساس بعدم الأمان } \\
\hline$\cdot, 7 \vee \wedge$ & $\cdot, T \vee Y$ & الدلالة المعنوبة & \\
\hline$\cdot, Y . O$ & $\cdot, Y \vee \varepsilon-$ & معامل الارتباط & \multirow{2}{*}{ العرضة للحوادث } \\
\hline$\cdot, 079$ & $\cdot, \leq \leqslant \leq$ & الدلالة المعنوية & \\
\hline$\cdot, Y \cdot T$ & •,YYT- & معامل الارتباط & \multirow{2}{*}{ الفقر } \\
\hline$\cdot, 0 V T$ &., 041 & الدلالة المعنوية & \\
\hline$\cdot, r \vee q$ & $\cdot, \leqslant \wedge 0$ & معامل الارتباط & \multirow{2}{*}{ عدم وجود مأوي } \\
\hline$\cdot, \leqslant$ \% & $\cdot, 100$ & الدلالة المعنوية & \\
\hline$\cdot, r \leqslant 0$ & $\cdot, Y V Y-$ & معامل الارتباط & \multirow{2}{*}{ التعرض للأمراض } \\
\hline$\cdot, \leqslant 9 \leqslant$ & $\cdot, \varepsilon \leqslant V$ & الدلالة المعنوبة & \\
\hline$\cdot, \Gamma \cdot 0$ & $\cdot, r 00-$ & معامل الارتباط & \multirow{2}{*}{ مشكلات المؤسسة } \\
\hline$\cdot, r q 1$ & $\cdot, \Sigma \vee V$ & الدلالة المعنوية & \\
\hline$\cdot, 1 \times 9$ & $\cdot, r) \leq-$ & معامل الارتباط & \multirow{2}{*}{ مشكلات الشعور } \\
\hline$\cdot, V Y Y$ & $\cdot r V V$ & الدلالة المعنوبة & \\
\hline י &., $.9 Y-$ & معامل الارتباط & \multirow{2}{*}{ إجمالي أبعاد المقياس } \\
\hline., $01 Y$ & $\cdot, \wedge \curlyvee \varepsilon$ & الدلالة المعنوية & \\
\hline
\end{tabular}


• إنه لا توجد علاقة إرتباطية بين الخصائص الإجتماعية وأبعاد المقياس ككل. • إنه لا توجد علاقة إرتباطية بين الخصائص الإجتماعية وبعد النقص والدونية. • إنه لاتوجد علاقة إرتباطية بين الخصائص الإجتماعية وبعد العدوان. • إنه لاتوجد علاقة إرتباطية بين الخصائص الإجتماعية وبعد الخوف من المستقبل.

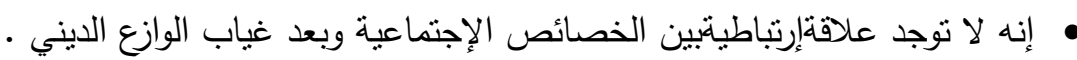

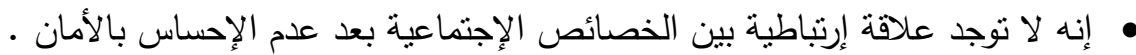
• إنه لا توجد علاقة إرتباطية بين الخصائص الإجتماعية بعد التعرض للحوادث .

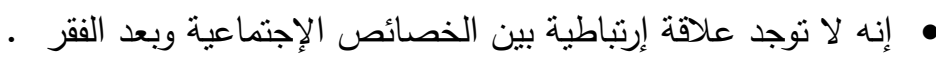
• إنه لا توجد علاقة إرتباطية بين الخصائص الإجتماعية وبعد عدم وجود مأوي أو سكن. الإجنه

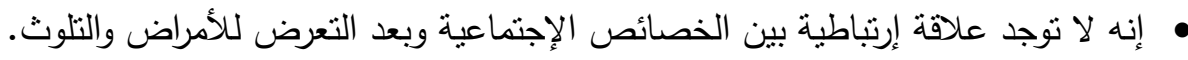

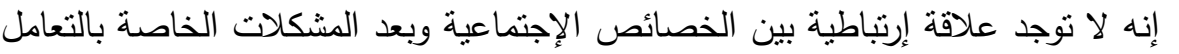

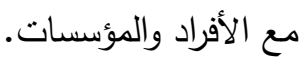
• إنه لا نوجد علاقة إرتباطية بين الخصائص الإجتماعية بعد الثعور بالانتماء للمجتمع. ومن هنا توصلت الاراسة لعدة نتائج هامة هى: ا ـ أنه توجد فروق ذات دلالة إحصائيا بين محل الإقامة ( المؤسسة/ الثارع ) وبين إجمالي لهائ

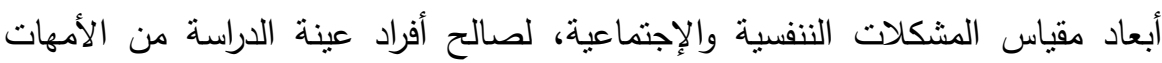

$$
\text { المتواجدات بالثنارع. }
$$

تري الباحثة أن ماسبق يتفق مع نظرية الحاجات لماسلو حيث إن أساس فكرة ماسلو هو نظريته في الدافعية حيث يري أن لدي الإنسان عدد من الحاجات الفطرية مرتبة في ترتيب

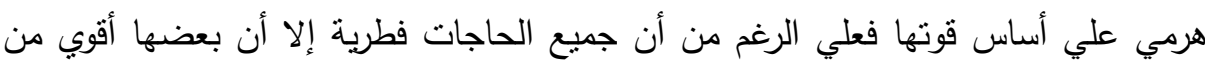

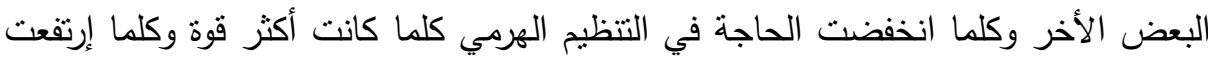
كلما كانت أضعف وقد رتب ماسلو هذه الحاجات كما يأتي: الحاجات الفسيولوجية - الحاجة للأمن والحاجة للحب والإنتماء والحاجه لتقدير الذات والحاجة لتحقيق الذات والحاجة لحل

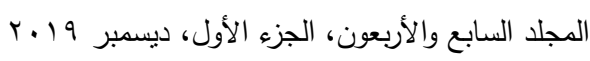


المشكلات والحاجة الجمالية، فيري ماسلو أن هناك مجموعة من الحاجات لدي الفرد تتحكم في ظهور المثكلات النفسية المختلفة عند عدم إثباع هذه الحاجات لدي طفلة الثارع الأم

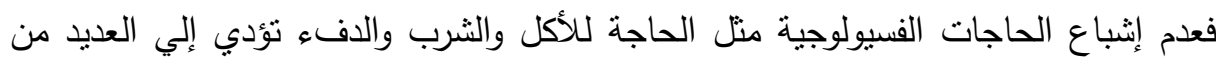
المشكلات النفسية مثل التعرض للحوادث، كما أن عدم إثباع الحاجة للأمن نتيجة نواجدها

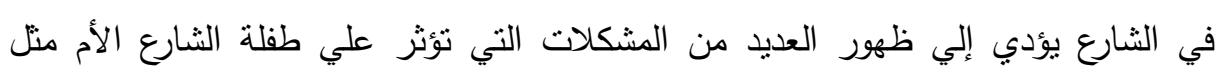

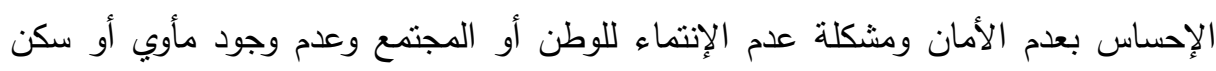

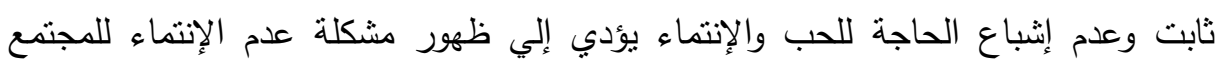

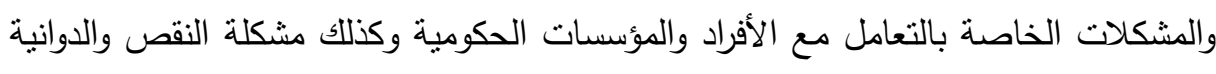

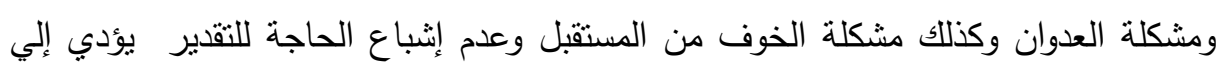
ظهور مشكلة النقص والدونية وكنلك مشكلة العدوان ومشكلة عدم الإحساس بالأمن، وهكذا

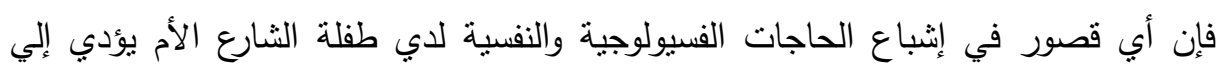

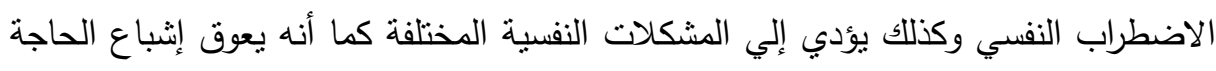
النفسية التي تليها وكلما كانت الحاجة النفسية التي أحدث قصور في إثباعها في قاعدة الهرم كلما كان ظهور المشكلة النفسية مبكرا.

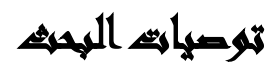

ا. مساعدة الأمهات الصغيرات علي الاستفاد من اقاتهم وقدراتهم في بعض الأعمال التي

$$
\text { تجلب لهم العائد المادي. }
$$

r. ضرورة التوعية الصحية لهؤلاء الأطفال وإعطائهم بعض الإرشادات في أماكن تواجدهم من

$$
\text { قبل المشرفين الإجتماعين. }
$$

r. العمل علي تعديل النظرة المتدنية لهم وإدماجهم في المجتمع، والعمل علي إحترام ادميتهم. ع. إنشاء المؤسسات المتخصصة لرعاية هؤلاء الفتيات. 


\section{مبانs:}

إدارة المؤسسات الأهلية في التصدي لمشكلة أطفال الثوارع. جمعية قرية الأمل وادارة الدراسات والبحوث والتنريب، القاهرة.

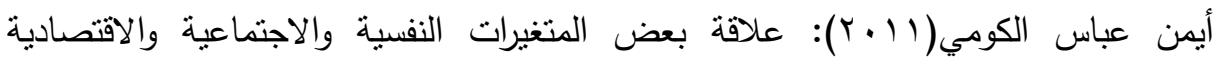

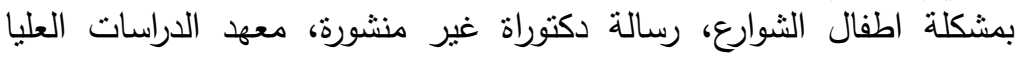

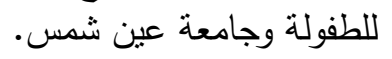

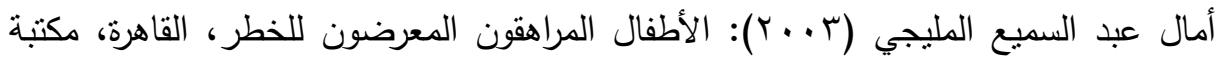

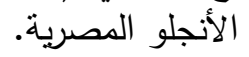

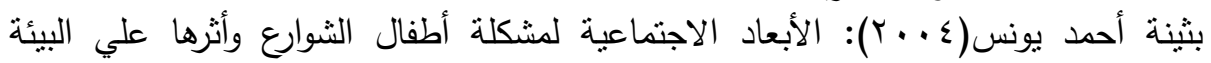

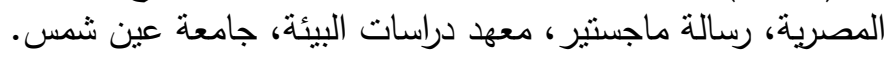

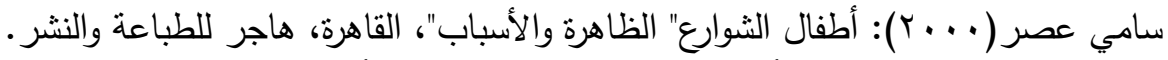

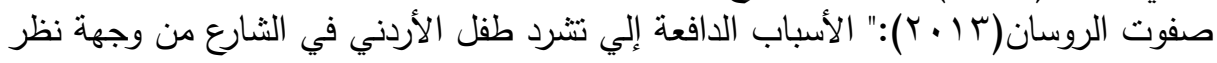

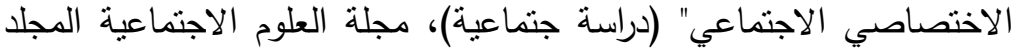

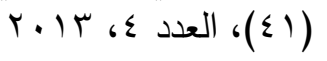

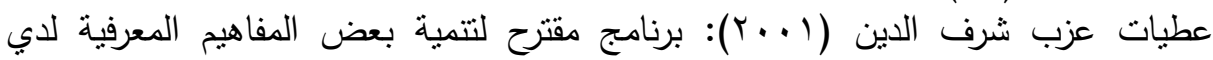

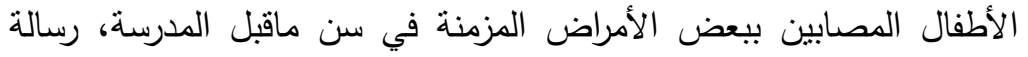

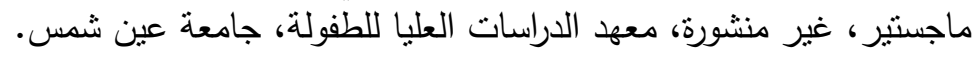

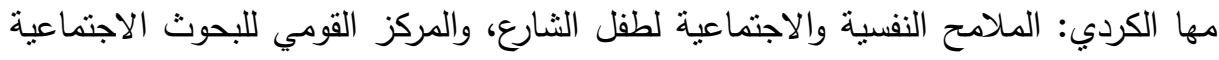

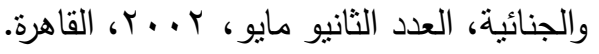

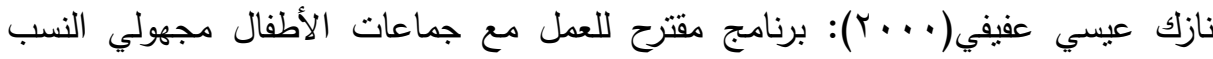

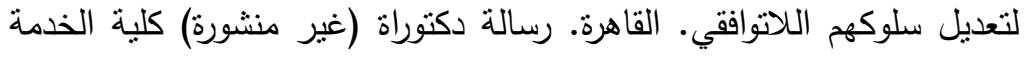

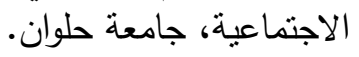

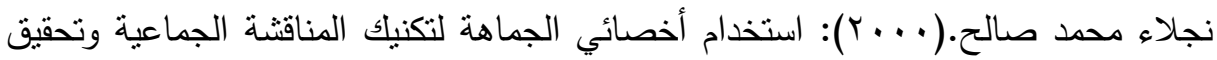

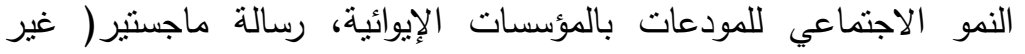

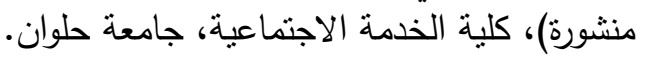

Bob franklin. 1986, the right of children ptg.u.s.al td: n.y. bleat well,p. Brom, charlotte, the human right's of child the case of street children in control ameria, university of Canada, vol, 15, 3003,p.212240 . 
Kabita chakrabort, streetchildren, thougth, and perception of the environment, university of toranto, Canada, vol 4103,2002,p703.

Tim mercer: family voices an ethnographic study of family characteristics and csregiver perspective on street children in eldoret, kenya, mph, yale university, usa, 2009.

\title{
PSYCHOLOGICAL AND SOCIAL PROBLEMS OF HOMELESS MOTHERS AND THE ROLE OF CIVIL EFFORTS IN CONFRONTING THEM
}

\author{
Hanan M. A. Salama(1); Ahmed M. Al-Atik ${ }^{(2)}$ \\ and Madiha M. Fathy ${ }^{(3)}$
}

1) Post Grad., Institute of Environmental Studies \& Research, Ain Shams University 2) Department of Environmental Humanities Sciences, Institute of Environmental Studies \& Research, Ain Shams University 3) Faculty of Social Work, Helwan University

\begin{abstract}
The present study aims at identifying the psychological and social problems facing the homeless young mothers, standing also on the differences between mothers in the care institutions and mothers living outside them (in street). The study focuses on the homeless young mothers in Al-Aml Village and Banaty Society in Cairo governorate. The study sample consists of (20) young mothers in Cairo governorate, divided as follows: (10) young mothers from within the care institution, and (10) young mothers from outside the care institution. The study relies on the analytical-descriptive method. Regarding the data collection, the researcher has used the (Psycho-Social Scale of the Young Mothers) to find out the relationship between the psychological and social problems and the place of residence. The researcher has relied on Maslow's Theory of Needs; since Maslow sees that there are a
\end{abstract}

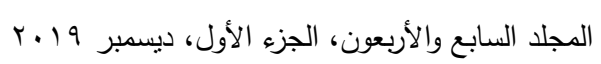


group of needs that control the individual the emergence of various psychological problems when they are unfulfilled. The dissatisfaction of physiological needs, such as the need to eat, drink and warm up, leads to many psychological problems such as exposure to accidents. In addition, the lack of satisfaction of the need for security as a result of their presence in the street leads to the emergence of many problems that affect the street mother's child, such problems are for instance, the sense of insecurity, the non-affiliation problem towards the state, or society, the absence of shelter or permanent housing and the dissatisfaction of the need for love and belonging which lead to the emergence of the non-belongingness problem towards the community.

The problems of shortage, pedophilia, and aggression as well as the problem of fear of the future and the dissatisfaction of the need for appreciation lead to the feeling of inferiority as well as aggression and the lack of sense of security. Thus, any failure to satisfy the physiological and psychological needs of the mother's child leads to psychological disorder and also leads to various psychological problems. The study has reached several results; there are statistically significant differences between location of residence and dimensions of scale of self-concept as a whole. There are also statistically significant differences between the place of residence (institution / street) and dimensions of scale of psychological and social problems, in favor of the street's girl 